\title{
Factors Affecting Conception Rate of Dairy Cows Following Artificial Insemination in Selected Area at Sirajgonj District of Bangladesh
}

\author{
Howlader MMR ${ }^{1 *}$, Rahman MM' ${ }^{1}$, Hossain $M^{2}$ and Hai $M^{3}$ \\ ${ }^{1}$ Department of Physiology, Bangladesh \\ ${ }^{2}$ Upozilla Livestock Officer, Bangladesh \\ ${ }^{3}$ Veterinary Surgeon, Bangladesh
}

Received: 制 January 07, 2019; Published: 制 January 18, 2019

*Corresponding author: Md. Matiar Rahman Howlader, Department of Physiology, Sylhet Agricultural University, Sylhet-3100, Bangladesh

\begin{abstract}
Conception Rate (CR) plays a major role to achieve a successful dairy farm. The present study was aimed to observe the conception rate of dairy cattle following artificial insemination (AI) in Sirajgonj district of Bangladesh. A total of 543 non descriptive indigenous and 317 crossbred cows were collected through face to face questionnaires with the farmers considering the breed, age, parity, retention of placenta, insemination after onset of estrous, calving interval and days open as potential risk factors affecting CR of cows. The collected data were analyzed by using SPSS software. The mean conception rate was 72 percent following AI. Cross breed cows (co-eff. $=-0.003, p<0.05$ ), removal of placenta $>6$ hours (co-eff. $=-0.17$, $p<0.05$ ), days open (co-eff. $=-.001, \mathrm{p}<0.01$ ) were identified as the risk factors for low CR after AI. Age of cow $<2.5$ years (co-eff. $=0.005$, p $>0.005)$, parity $>5$, (co-eff. $=0.210, p>0.05$ ), Insemination after onset of estrous $<3$ hours (co-eff. $=0.008, p>0.05$ ), calving interval $>551$ (co-eff. $=0.00$, $p>0.05$ ) were associated with the risk for lower CR following AI. Therefore, it could be stated that conception rate depends on various factors.
\end{abstract}

Keywords: Conception Rate; Artificial Insemination; Dairy cows

Abbreviations: GDP: Gross Domestic Product; CR: Conception Rate; AI: Artificial Insemination; BBS: Bangladesh Bureu of Statistics; PFOT: Parturition to First Oestrus Interval; PCI: Parturition to Conception Interval; FSCI: First Service to Conception Interval

\section{Introduction}

Bangladesh is an agriculture based country and livestock sharing 14.21\% in Gross Domestic Product (GDP) of Agricultural sector in the years of 2015-16 Bangladesh Bureau of Statistics [1]. In Bangladesh, livestock contributes $1.66 \%$ of total (GDP) and $3.21 \%$ in the growth rate of GDP BBS [1]. Dairy is one of the major components in livestock sector. About $20 \%$ of the total population is directly or indirectly involved in dairy sector or dairy farming Shamsuddoha et al. [2]. To attain the higher fertility rate is the common goal for profitable dairy farming. Getting cows pregnant in appropriate time is very important in operating a profitable dairy business or farm. Reproductive performances has declined over the last 25 years in dairy cows, with an increased number of days open and decreased conception rates Silvia [3]. Cow's fertility is commonly measured by calculating percentage of cows that conceive after a single Artificial Insemination (AI), and it is known as the conception rate (CR). An analysis of dairy herd records suggested one of the following areas: breeding policy (waiting too long after calving for first service), estrous detection efficiency for lower CR Smith [4].

AI has been using for intensive cross breeding program in Bangladesh since 1935 Ahmed et al. [5]. The success of AI technique depends on several factors Uuintela et al. [6]. The optimum conception rates will be achieved if good quality of semen is used, the insemination is done at the most appropriate time in relation to the estrous period, and the skills of the technician in the procedure. To keep profitable, a dairy cow needs to produce one calf at 12 to 14 months interval. One of the major constrains of profitable dairy farming is low CR Alam et al. [7]. Economically sustainable of dairy 
farming largely depends on a CR after AI. The twelve-month calving interval is advantageous for maximal milkyield per cow per yearwith good economic return (Opsomer et al., 1996). Conception rates are influenced by a variety of factors. Management and environmental factors account for $96 \%$ of the variation in conception rates. Herd differences in nutrition, metabolic disorders, reproductive health, heat detection, insemination practices and climate could influence significant differences in conception rates Kathy Lee [8].

The remaining $4 \%$ of variation in conception rates is due to genetic factors with $3 \%$ for the cow and $1 \%$ for the service bull Kathy Lee [8]. These small values indicate that improvement in conception rates due to genetic selection will occur at a relatively slow rate. The effects of the factors on CR need to assess, so that the appropriate measures to improve the CR could be adopted. The objective of this study was to determine the extent of influence of the factors related to the cow, AI service on the CR of dairy cows under smallholder production system such as to identify the various risk factors affecting the conception rate following artificial insemination, improve the different reproductive traits of dairy cows through AI service.

\section{Methodology}

A total of 320 questionnaires were filled up to collect related data during artificial insemination (AI) and natural insemination and subsequently pregnancy diagnosis were done after three months of AI at different upazilla veterinary hospitals of Sirajgonj district. All the data collected from the farmers were analyzed and a table was prepared on the basis of the objective of the study. The various factors investigated were:

a) Age of animals-the age of the animals was 2 years to more than 6 years.

b) Breeds of animal- two types of breed non-descriptive indigenous and crossbred dairy cows were included.

c) Type of insemination-considering artificial insemination only.

d) Time of insemination after onset of estrous- when the insemination was done after the cows came into estrous it varies from less than 3 hours to more than 18 hours.

e) Calving interval-calving interval of the cows were varies from 330 days to 750 days.

f) Parity number- parity number was ranged from 0 to more than 5.

g) Days open- days open of cows were varies from 30 days to 635 days.

h) Removal of placenta were measured in hours after insemination.

Data were analyzed to detect the conception rate (\%) for individual factor using MS excel and SPSS for regression analysis software package.

\section{Discussion}

Practically, it is difficult to find out the effect of cow genotype on their CR disregarding other factors including environmental and management conditions those might have much more influence on CR. Coung et al. [9] observed that higher conception rate in Holstein $\times$ Vietnamese crossbreds in the rainy season. In Bangladesh, Ghosh [10] found no difference in first service conception rate for different genotypes of cow $(50.0,43.8,50.0,43.8$ and 43.8\% for Friesian $\times$ Local, Sahiwal $\times$ Local, Sahiwal $\times$ Local, Friesian $\times$ Sahiwal $\times$ Local, Jersey $\times$ Local and Sahiwal $\times$ Local cows, respectively) in the small dairy enterprises at the village level of Gazipur district. Ghosh [11] found overall conception rates of several genotypes to be more or less similar in the rural areas of Bangladesh. However, the conception rates varied within the same breed at different location. Alam [12] observed more or less similar conception rates for different genotypes, although it varied within the same breed at different areas and different seasons.

The results of the present study were in agreement with the findings of Ghosh [11]; Alam [12], Ghosh [10], Gwazdauskas et al. [13] and in partial agreement with the reports of Rao et al and Coung et al. [9] Thus, no significant difference in cow fertility existed among the genotype of cows studied. A first service CR above $60 \%$ normally indicates a good reproductive efficiency of a dairy herd. On this basis, the first service CR obtained in the present study (50\%) reflected a satisfactory reproductive efficiency. It was higher than the average first service CR (40.9\%) obtained in 14 countries which ranged from $15.1 \%$ to $62.1 \%$ Garcia et al. [14,15]. These findings were in partial agreement with the report of Spalding et al. [16]. They reported that a slight increasing in fertility up to 3-4 years of age with subsequent declined in the following years of age. They found a marked declining in fertility in cows over 7 years of age. De Kruif [17] observed that lower conception rate following the first insemination after 7 years of age.

Similar results were reported by Barkett et al. [18]. The conception rate was increased slightly with the increasing of number of parity. In this study, at parity-3, the conception rate was high and after that it was found to decrease. These findings were similar with Sarder [19] who observed the influences of parity in CR. It showed that parturition to first oestrus interval (PFOT), Parturition to Conception Interval (PCI), first service to conception interval (FSCI) and service per conception (S/C) were shorter in higher parities group than in first parity. The third parity cows required shorter PFO $(105.8 \pm 7.1$ days $)$ than did the first $(127.8 \pm$ 10.6 days) and the second parity ones (117.4 \pm 5.6 days). As found in this study, CR tended to increase with increased parity number up to parity no. 3 which was similar to the report by Gwazdauskas et al. [20] where CR showed significantly higher values in cows of first parity than the fourth parity. However, it differed from other studies reported by Chung et al. [21] and Hla et al. [22], who found that CR tended to increase with the parity number. In this study, it was found that when the placenta removed within 3 hours, the conception rate was higher and differed significantly $(\mathrm{p}<0.05)$. Highest conception rate found at the time of removal of placenta of 0.5 to 1 hour. Lowest rate of conception was found at time of 4 hours or more.

These findings are similar with the following researcher who reported that the fertility of the dairy cows is affected when most cows in the herd suffer from retained placenta. These causes direct loss to the farmer due to delayed calving leading to a higher 
period between giving births (calving intervals) and hence low milk production. The adverse effects of RFM on reproductive performance of cattle are: delay in first service Stevens et al. [23] 5 , reduction of pregnancy rate Mc Dougall [24], increase in services per conception Holt et al. [25]. The RFM also leads to endometritis, puperal metritis and mastitis Bruun et al. [26] and these diseases ultimately cause the reduction in the fertility and milk production of cattle Laven et al. [27]. For obtaining highest conception rate in a dairy herd to run the farm profitably, it is important to breed the cows at a time that will ensure that healthy, live sperm are present at the site of fertilization when the unfertilized egg arrives. Thus, it is needed to know the time of insemination after the onset of estrous that depend on to ovulation.

This is based on the fact that ovulation occurs 24 to 30 hours after the animal first stands to be mounted Mufti et al. [28]. These results are more or less similar with the findings of Trimberger et al. [29]; Bane [30]; Roberts [31], who reported that the insemination rate was higher when the cows inseminated between the middle and the end of the period of oestrus. When insemination is carried out during the early part of oestrus, fewer cows will conceive, particularly when the semen is of indifferent or inferior quality. Inseminations carried out after ovulation has occurred will also result in lower pregnancy rates Trimberger et al. [29]; Boyd [32]; Deas [33]. It showed increasing calving interval decreased conception rate causes economic loss are mainly due to a loss of production as a result of prolonged calving intervals having similaritie with these researchers Van Arendonk et al. [34]; Olori et al. [35] and also includes increased insemination costs, reduced returns from calves born and higher replacement costs Bagnato et al. [36], Nilforooshan et al. [37] stated that age at first calving significantly affected traits, including milk yield, fat percentage, lifetime and productive life. The conception rate found to decrease with the increased of days open period significantly $(\mathrm{p}<0.01)$. The results of this study are in agreement with the reports of Dohoo [38] who found that increasing the open interval of cows reducing the breeding value such as fertility or conception rate of cows.

\section{Results}

The fertility data on a total of 860 cows were collected in this experiment to investigate the effect of breed, age, parity, body condition, cow in milk or dry and feeding category. Out of the 860 cows and heifers 620 were pregnant (72\%). Descriptive analysis was expressed as the Regression analyses to measure the association and strength of association between the potential influencing factors as: age, breed, parity, removal of placenta (hour), insemination after onset of estrous, calving interval and days open. The outcomes variable were influenced the conception rate.

\section{Effects of Breed on Conception Rate}

In this study, the $\mathrm{CR}$ of local, $\mathrm{L} \times \mathrm{F}$, is $73.98 \%, 70.02 \%$, respectively (Figure 1). It means in case of cross breed, it had high risk for low conception rate (co-eff. $=-0.003, p>0.05$ ) shown in the Table 1 . The highest conception rate found in non-descriptive indigenous cows that differed significantly $(\mathrm{p}<0.05)$ than the crossbred cows.

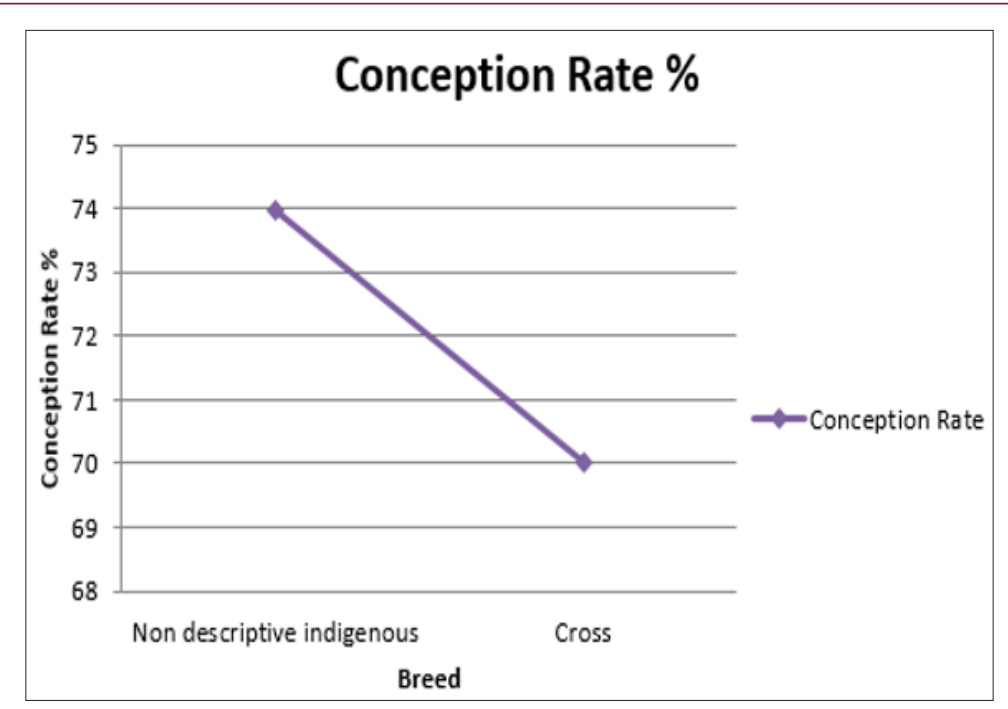

Figure 1: Effects of breed on conception rate.

\section{Effects of Age on Conception Rate}

The cows aged $<2.5,2.5$ to $3.5,3.6$ to $4.5,4.6$ to 6 , $>6$ years found $50 \%, 71.93 \%, 78.06 \%, 85.49 \%, 74.52 \%$ conception rate after first AI, respectively (Figure 2). The effect of age on conception rate in 3 to 6 years of age increased in the present study and fallen afterwards (co-eff. $=0.005, \mathrm{p}>0.05$ ) shown in the Table 1 . The conception rate $58.25 \%, 74.29 \%, 76.58 \%, 81.14 \%, 76.93 \%$, $64.81 \%$ observed in parity-o, parity-1, parity-2, parity-3, parity-4, parity-5 or more, respectively (Figure 3 ). The effect of parity has low positive correlation (co-eff. $=0.21$ ) and differ significantly $(\mathrm{p}<0.01$, Table 1$)$ on conception rate. 


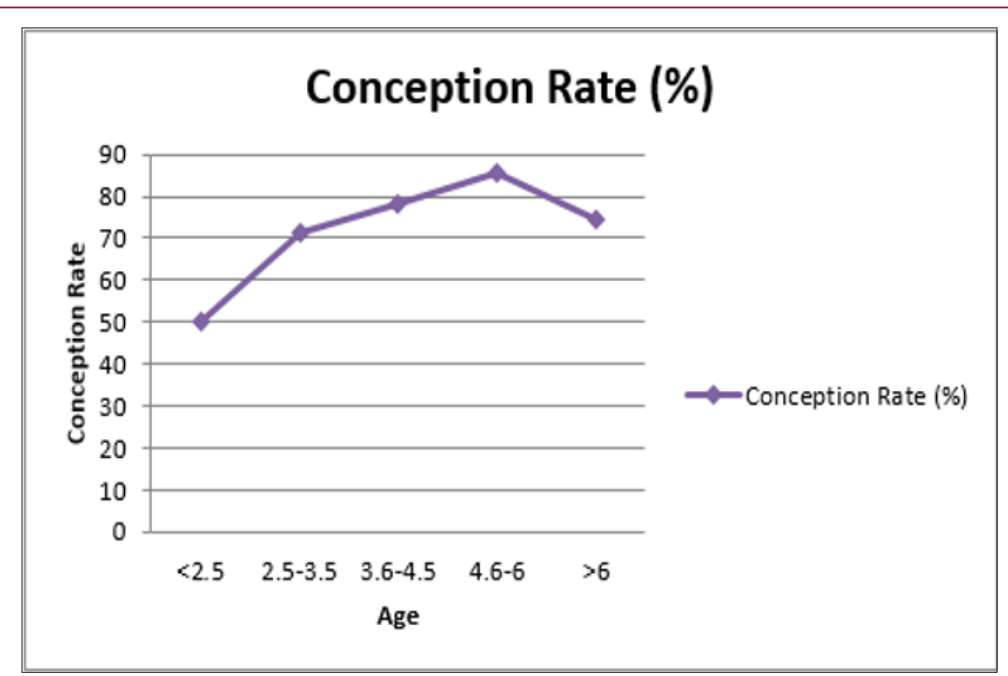

Figure 2: Effects of age on conception rate.

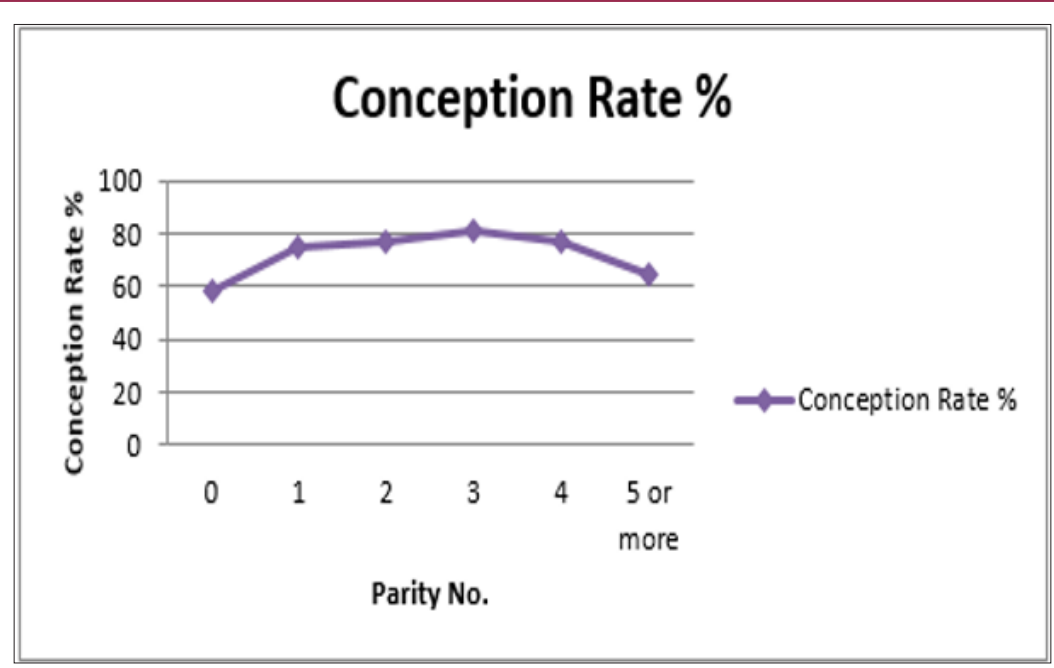

Figure 3: Effects of parity on conception rate.

Table 1: Regression analysis for the dependent and independent variables (age, breed, parity, Removal of placenta (hour), insemination after onset of estrous, calving interval and days open).

\begin{tabular}{|c|c|c|c|c|c|c|c|}
\hline \multirow{2}{*}{\multicolumn{2}{|c|}{$\begin{array}{c}\text { Variable } \\
\text { Age of cow }\end{array}$}} & \multirow{3}{*}{$\begin{array}{c}\text { Co-efficient } \\
0.005 \\
0.01\end{array}$} & \multirow{3}{*}{$\begin{array}{c}\text { Standard Error } \\
0.029 \\
0.004\end{array}$} & \multirow{3}{*}{\begin{tabular}{c|} 
P-Value \\
0.871 \\
$.014^{*}$
\end{tabular}} & \multirow{3}{*}{\begin{tabular}{|c|} 
T Value \\
0.162 \\
2.498
\end{tabular}} & \multicolumn{2}{|c|}{ 95\% Confidence Interval } \\
\hline & & & & & & -0.052 & 0.061 \\
\hline \multirow[t]{2}{*}{ Breed of cow } & $\begin{array}{l}\text { Non descriptive } \\
\text { indigenous }\end{array}$ & & & & & 0.002 & 0.017 \\
\hline & Cross & -0.003 & 0.006 & 0.661 & -0.44 & -0.015 & 0.009 \\
\hline \multicolumn{2}{|c|}{ Parity number } & 0.21 & 0.034 & 0.537 & -0.619 & -0.089 & 0.046 \\
\hline \multicolumn{2}{|c|}{ Removal of placenta (hour) } & -0.017 & 0.008 & $.029^{*}$ & -2.208 & -0.002 & 0.033 \\
\hline \multicolumn{2}{|c|}{$\begin{array}{l}\text { Insemination after onset of } \\
\text { estrous(hour) }\end{array}$} & 0.008 & 0.006 & 0.189 & 1.32 & -0.004 & 0.02 \\
\hline \multicolumn{2}{|c|}{ Calving interval (days) } & 0 & 0 & 0.568 & 0.573 & -0.001 & 0.001 \\
\hline \multicolumn{2}{|c|}{ Days open (days) } & -0.001 & 0 & $.006^{* *}$ & -2.784 & -0.001 & 0.001 \\
\hline
\end{tabular}

**Means 0.01 level of significance *Means 0.05 level of significance

NS $=$ Not significance

\section{Effect of Time of Removal of Placenta on Conception Rate}

In dairy cows that retained placenta may be the cause of serious economic losses to the farmers as cows with retained placenta may reduce conception rate of dairy cows. This causes a direct loss to the farmer due to delayed calving leading to a higher period between giving births (calving intervals) and hence low milk production Tucho [39]. In the Figure 4, the conception rate of cows found 
$80.66 \%, 78.95 \%, 75.60 \%, 70 \%, 68.96 \%, 65.55 \%$ and $64.28 \%$ in relation to the time of removal of placenta were 0.5 to 1 hour, 1.1 to 2 hours, 2.1 to 3 hours, 3.1 to 4 hours, 4.1 to 5 hours, 5.1 to 6 hours, and $>6$ hours, respectively (co.eff $=-.017$. Table 1 ). It showed that the conception rate decreased with the increased time of removal of placenta duration.

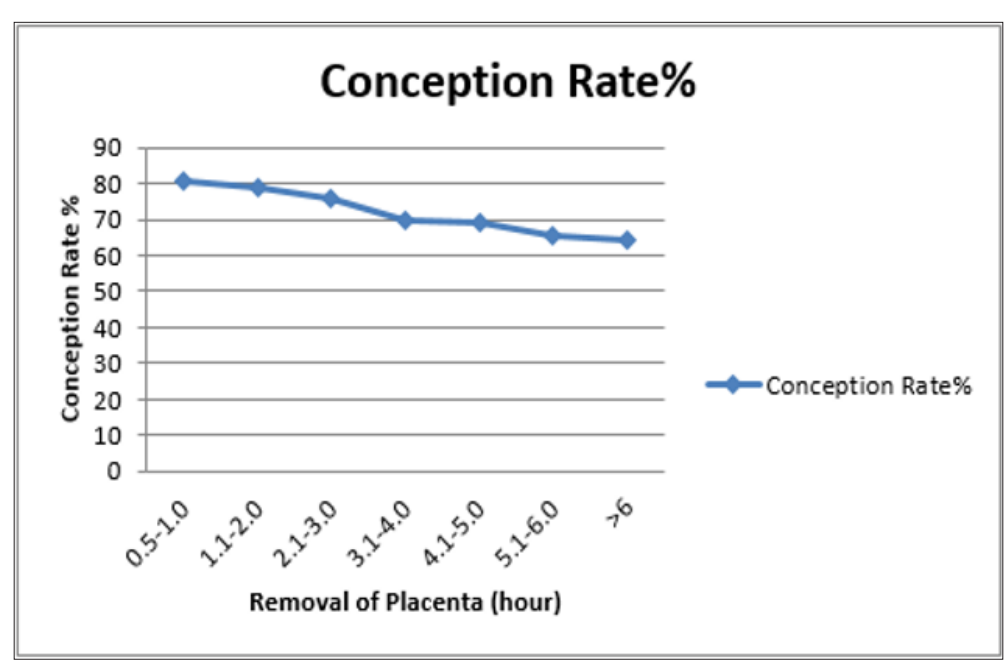

Figure 4: Effects of time of removal of placenta on conception rate.

\section{Effects of Time of Insemination on Conception Rate}

In the field condition, inseminator practices variable time during AI in Shirajgonj district. Most of the farmers replied that after the onset of estrous of cows were being inseminated from 3 to $>22$ hours after the onset of estrous [40]. The highest 3 values of conception rate found when inseminated in between 9.1 to 12 hours, 12.1 to 15 hours and 15.1 to 18 hours after onset of estrous and the values were $78.06 \%, 80.36 \%$ and $76.61 \%$, respectively (co.eff $=0.008$, Table 1 ) On the other hand, the conception rates of cows inseminated in less than 3 hours and 18 to above were $65 \%$ and $69.26 \%$, respectively that lower than the expected mean value (Figure 5).

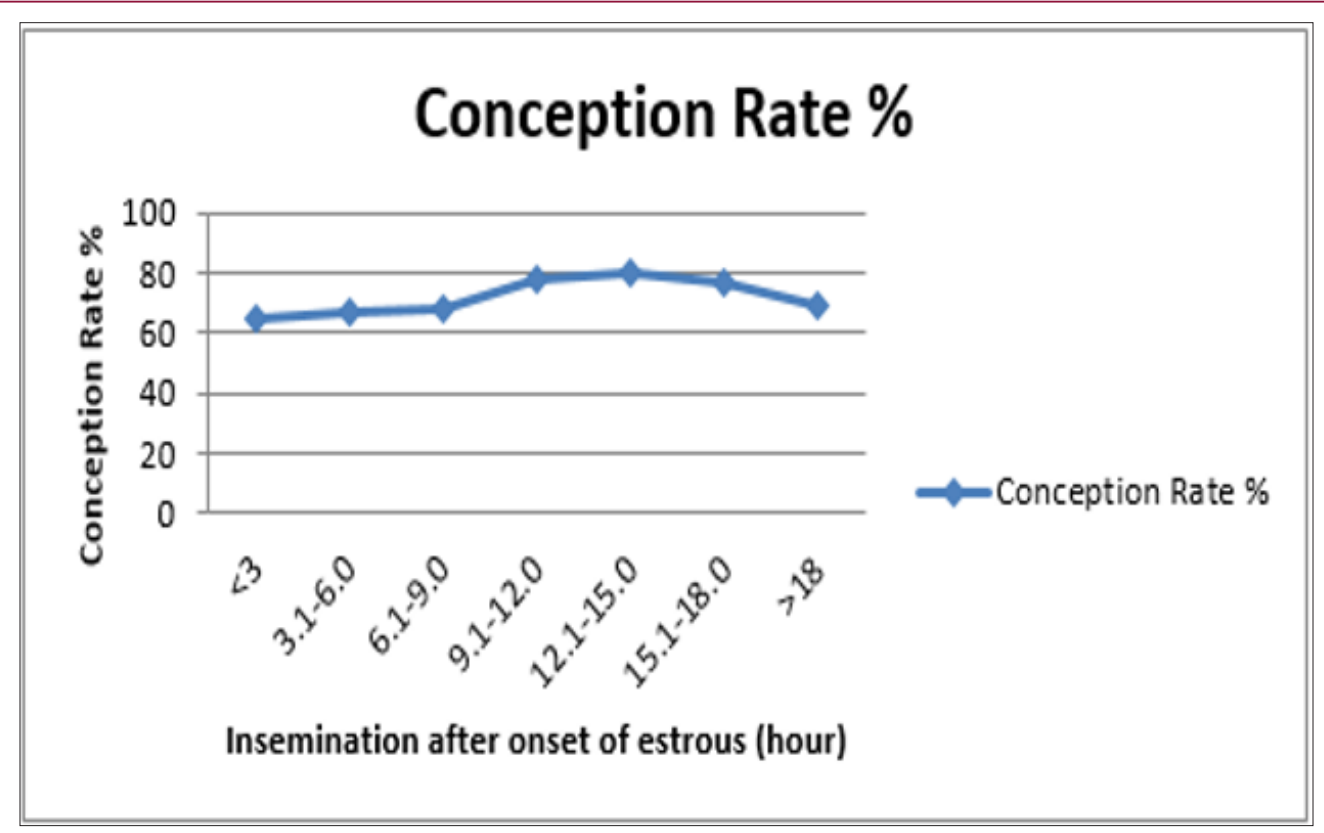

Figure 5: Effects of time of insemination on conception rate.

\section{Effects of Calving Interval on Conception Rate}

In this study, the conception rate decreased with the increased calving interval but did not differ significantly. Highest conception rate found $81.19 \%$ in calving interval between 330-365 days. Lowest conception rate found $63.60 \%$ in calving interval between 550-75 days (Figure 6). 


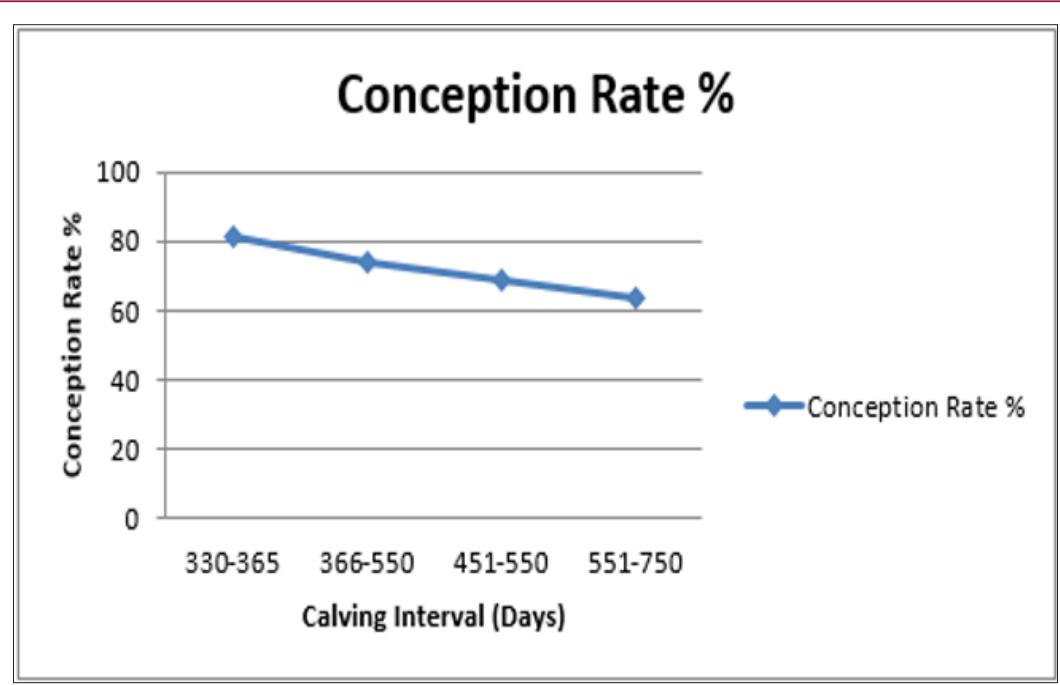

Figure 6: Effects of calving interval on conception rate.

\section{Effects of Days Open on Conception Rate}

The conception rates found $84.31 \%, 70.54 \%, 68.15 \%$ and $65.00 \%$ in the calving interval of $30-150$ days, $151-270$ days, 271-540 and 401-635, respectively. This study showed that the days open has got negative correlation (co-eff.= -.001, Table 1) that differ significantly $(\mathrm{p}<0.001)$ on conception rate. The highest conception rate found 30 to 150 days. In relation with this, the lowest conception was recorded $65 \%$ in the days open interval at 401-635 days (Figure 7).

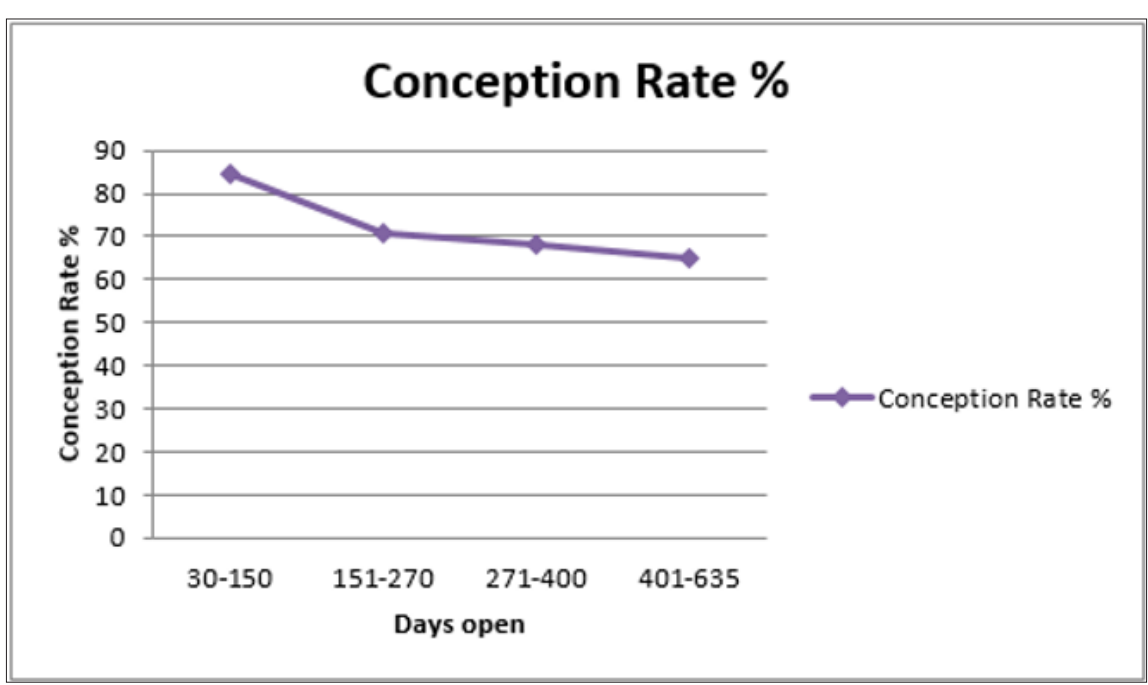

Figure 7: Effects of Days Open on conception rate.

\section{Conclusion}

The conception rate (CR) in dairy cows under smallholder production system in Bangladesh was influenced by some degrees of factors related to the cow, farm, AI technician and bull. The CR was significantly affected by the breed of cow, age of cow, parity number and insemination time. The CR was higher in non-descriptive indigenous cow than that of crossbred [41]. The conception rate was found to increase from the pubertal age to 6 years and then gradually fall down with the increased of age The CR recorded higher in cows with lower parity number up to parity number 4 and then gradually tend to decrease. The CR also found to be lower in farms that performed AI very early after onset of estrous and very late more than 18 hours of estrous. Highest CR was recorded within the middle period of estrous 9 to 15 hours of estrous. Negative correlation was found with days open. The CR found to decrease with the increase of calving interval and days open. Retention of placenta showed negative impact on CR in this study. Therefore, to improve the CR one should consider all factors related to the cow, farm, AI services, bull and applying the practices recommended for the cow to conceive.

\section{References}

1. (2016) Bangladesh Bureau of Statistics. Year Book of Agricultural Statistics of Bangladesh. Bangladesh Bureau of Statistics. Ministry of Planning, Government of the Peoples' Republic of Bangladesh.

2. Shamsuddoha AK, Edwards G (2000) Dairy Industry in Bangladesh: Problems and Prospects. Paper for AARES 2000 Conference School of Business La Trobe University.

3. Silvia KD (1998) Factor affecting conception rate. Dairy Integrated Reproduction Management, IRM-10, Cornell University, USA, p. 1-5. 
4. Smith D, R Charles, R Sniffen, S David, Kronfeld (1985) Path Analysis of Dry Period Nutrition, Postpartum Metabolic and Reproductive Disorders, and Mastitis in Holstein Cows. J Dairy Sci 68(9): 2347-2360.

5. Ahmed Z, TS Islam (1987) Breeding programme through artificial Insemination in Bangladesh. Artificial Insemination Extension Project, Central Cattle Breeding Station, Department of Livestock Service, Savar, Dhaka, Bangladesh, p. 1-68.

6. Uuintela JT, Arndt EP (2004) Fertility of two bulls with poor sperm morphology. Journal of the South African Veterinary Association 66(2): 74-76.

7. Alam J (1994) Comparative performance of local and crossbred cows in Bangladesh. Final Report of the Research Project. Bangladesh Livestock Research Institute. Savar, Dhaka.

8. Kathy L (2004) AI bulls ranked by conception rates. Michigan Dairy Review p. 1-3.

9. Cuong LX, LV Tan, CA Dung, DP Chung, VN Long (1993) Study on the effect of season and genotype on the reproductive performance in crossbred cattle. Proceeding of the Final Research Co-ordination meeting, Bangkok, Thailand.

10. Ghosh DK (1995) Economic traits of cross breed cattle in small dairy enterprises of gazipur district. Msc Thesis, Department of Physiology, Bangladesh Agricultural University, Mymensingh.

11. Ghosh DK (1990) Reproductive performance of Zebu, cows and their crosses with references to progesterone conceptions during the oestrus cycle, early pregnancy and postpartum period, MSc Thesis, Department of Surgery and Obstetrics, Bangladesh Agricultural University, Mymensingh.

12. Alam MGS (1991) Studies on current reproductive status with special emphasis on endocrine disorders in cow. Final report of the Research Project. Bangladesh Agricultural Research Council, Farmgate, Dhaka.

13. Gwazdauskas FC, CJ Wilcox, WW Thatcher (1975) Environmental and managemental factors affecting conception rate in a subtropical climate. Journal Dairy Science 58(1): 88-92.

14. Rao AVM, MS Naidu, YN Murthy (1992) Effects of breed type and season on conception rates in cows. World Review of Animal Production 27(3): 23-25.

15. Garcia M, WJ Goodger, T Bennett, BMAO Perera (2001) Use of standardized protocol to identify factors affecting the efficiency of artificial insemination services for cattle through progesterone measurement in fourteen countries. Proc of final Research Co-ordination Meeting (IAEA-TECDOC-1220) on 'Radioimmunoassay and related techniques to improve artificial insemination programmes for cattle reared under tropicaland sub-tropical conditions', IAEATECDOC-1220 pp. 173-184.

16. Spalding RW, RW Everett, RH Foote (1975) Fertility in New York artificially inseminated Holstein herds in dairy herd improvement Journal of Dairy Science 58(5): 718-723.

17. De Kruif A (1978) Factors influencing the fertility of a cattle population. Journal of Reproduction and Fertility 54(2): 507-518.

18. Barkett LJ (1986) Dairy merit of temperate and tropical cross-bred cows at the Sylhet Government Dairy Farm. Bangladesh Veterinary Journal 29: 57-61.

19. Sarder MJU (2001) Reproductive and productive performance of indigenous cows. The Bangladesh Veterinarian 18(2): 123-129.

20. Gwazdauskas FC, JA Lineweaver, WE Vinson (1981) Rates of conception by artificial insemination of dairy cattle. Journal Dairy science 64(2) : 358-362.

21. Chung DP, PH Hai (2001) Constraints on efficiency of artificial insemination and effect of nutrition on reproductive performance in dairy cattle smallholder farms in Vietnam. Proc of final Research
Coordination Meeting on 'Radioimmunoassay and related techniques to improve artificial insemination programmes for cattle reared under tropical and sub-tropical conditions', IAEA-TECDOC-1220 p. 67 -78.

22. Hla UT, UA Myatt, DSS Kyi and YH Win (2001) Improvement of cattle production in Myanmar through the use of progesterone RIA to increase efficiency and quality of artificial insemination services. Proc of final Research Co-ordination Meeting on Radioimmunoassay and related techniques to improve artificial insemination programmes for cattle reared under tropical and subtropical conditions', IAEA-TECDOC-1220, p. $45-50$.

23. Stevens RD, RP Dinsmore RP (1997) Treatment of dairy cows at parturition with prostaglandin F2 a or oxytocin for prevention of retained fetal membranes. J Am Vet Med Assoc 211(10): 1280-1284.

24. McDougall S (2001) Effects of periparturient diseases and conditions on the reproductive performance of New Zealand dairy cows. NZ Vet J 49(2): 60-68.

25. Holt LC, WD Whittier and FC Gwazdauskas (1989) Early postpartum reproductive profiles in Holstein cows with retainedplacenta and uterine discharges. J Dairy Sci 72(2): 533-539.

26. Bruun J, AK Ersb, L Alban (2002) Risk factors for metritis in Danish dairy cows. Prev Vet Med 54(2): 179 -190.

27. Laven RA, AR Peters (1996) Bovine retained placenta: Aetiology, pathogenesis, and economic loss. Vet Rec 139(19): 465-471.

28. Mufti MMR, MK Alam, MS Sarker, ABMR Bostami and NG Das (2010) Study on factors affecting the conception rate in red chittagong cows. Bang J Anim Sci 39(1\&2): 52-57.

29. Trimberger GW, GK Davis (1943) The relationship between time of insemination and breeding efficiency in dairy cattle. Res Bull Neb agrie Exp Stn No pp. 129.

30. Bane (1964) Fertility and reproductive disorders in Swedish cattle. $\mathrm{Br}$ Vet J 120(9): 431-441.

31. Roberts SJ (1971) Veterinary Obstetrics and Genital Diseases. Edwards Brothers, Inc., Ann Arbor, Michigan.

32. Boyd LJ (1970) Managing dairy cattle for infertility. Journal Dairy Science 53(7): 969-972.

33. Deas DW (1970) The timing of insemination. Veterinary Research 88: 450-451.

34.Van Arendonk JAM, R Hovenier, W De Boer (1989) Phenotypic and genetic association between fertility and production in dairy cows. Livest Prod Sci 21(1): 1-12.

35. Olori VE, Meuwissen, RF Veerkamp (2002) Calving interval and survival breeding values as a measure of cow fertility in a pasture-based production system with seasonal calving. J Dairy Sci 85(3): 689-696.

36. Bagnato A, PA Oltenacu (1994) Phenotypic evaluation of fertility traits and their association with milk production of Italian Friesian cattle. J Anim Sci 77(3): 874-882.

37. Nilforooshan MA, MA Edriss (2004) Effect of age at first calving on some productive and longevity traits in Iranian Holsteins of Isfahan Province. J Dairy Sci 87(7): 2130-2135.

38. Dohoo IR (1983) Cost of extended open period in dairy cattle. Can Vet J 23(7): 229-230.

39. Tucho TT (2017) Review on retention of placenta in dairy cows and it is economic and reproductive impacts. Journal of Natural Sciences Research 7(7).

40. Alam J (1993) Livestock: the sector for more investment in Bangladesh. Asian Livestock 7: 77-81.

41. Opsomer HT (1996) Factors affecting coiled tail spermatozoa in the bull. American Journal of Veterinary Research 23: 300-308. 


\section{ISSN: 2574-1241}

DOI: $10.26717 / B J S T R .2019 .13 .002386$

Howlader MMR. Biomed J Sci \& Tech Res

(C) This work is licensed under Creative

Submission Link: https://biomedres.us/submit-manuscript.php

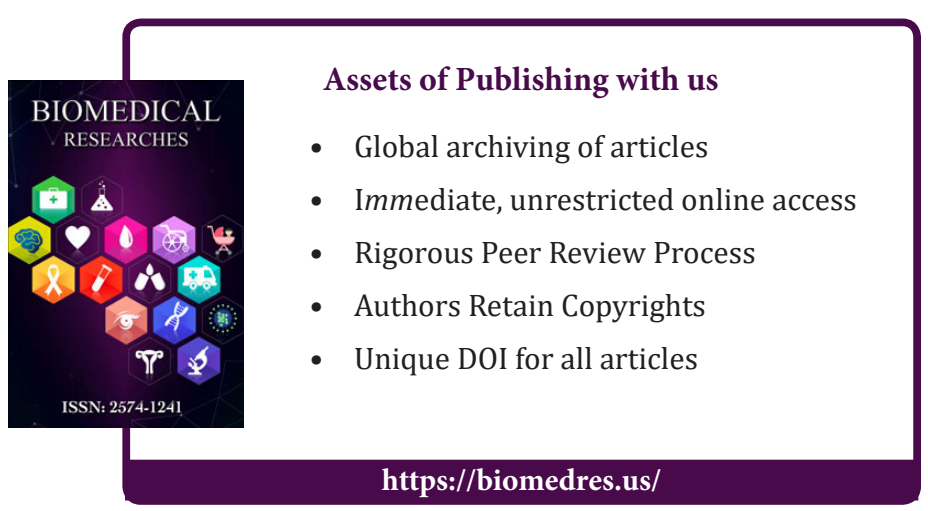

